\title{
Computational Fluid Dynamics Analysis of the Aortic Coarctation
}

\author{
Fatima Moumen ${ }^{*}$, Abed-El-Farid Djemaï ${ }^{2}$ \\ ${ }^{1}$ Department of Physics, Faculty of Exact and Applied Sciences, University of Oran 1 Ahmed BENBELLA, \\ Oran, Algeria \\ ${ }^{2}$ Department of Physics Engineering, Faculty of Physics, University of Sciences and Technologies \\ Mohamed BOUDIAF, USTO-MB, Oran, Algeria \\ Email: *fmoumen@yahoo.fr, abedelfarid@yahoo.com
}

Received 24 May 2016; accepted 21 June 2016; published 24 June 2016

Copyright (C) 2016 by authors and Scientific Research Publishing Inc.

This work is licensed under the Creative Commons Attribution International License (CC BY). http://creativecommons.org/licenses/by/4.0/

c) (i) Open Access

\begin{abstract}
In this work, we first investigated the hemodynamic parameters in the case of a normal aortic arch anatomy and in the case of aortic coarctation anatomy, both generated by using CFX-ICEM-ANSYS simulations. Then, we compared these results with those obtained for a proposed model without and with aortic coarctation, while introducing a real tridimensional magnetic resonance imaging geometry in the simulation process. The conclusion is that our proposed model reproduces, with a high agreement, the real case obtained from imaging data.
\end{abstract}

\section{Keywords}

Hemodynamic Parameters, Aortic Coarctation, CFX-ICEM-ANSYS Code, Computational Simulation, Magnetic Resonance Imaging (MRI) Data

\section{Introduction}

One of the main goals for numerical investigations of the blood flow in the thoracic aorta, and in particular in the aortic arch, is to well understand changes flow patterns and associated pressures in the presence of aortic pathologies, such as aortic coarctation or atherosclerotic diseases. Indeed, aortic coarctation induces an internal geometry deformation of the aortic wall, which induces at its turn significant changes in the hemodynamic characteristics of the flow. These phenomena would affect the normal blood circulation, and strong turbulence would occur, and then affect the aortic wall, leading ultimately to the need of surgical intervention to avoid fatal events.

*Corresponding author. 
More precisely, the aortic coarctation is a narrowing in the aorta (Figure 1) [1], in general located just after the left subclavian bifurcation. It is one of the most common congenital aortic diseases, affecting 1/10,000 of the human population. Moreover, a large proportion (10\% - 20\%), treated during the neonatal period, develop recoarctation. The fundamental problem with the presence of a coarctation is that it increases the after-load on the heart, reducing flow and increasing cardiac and vascular pressures proximal to the coarctation, leading to an increase risk of cardiovascular events and strokes [2] [3].

This aortic disease appears as a good physiological and physical problem which needs to be treated theoretically using the fluid mechanics tools, experimentally by using medical imaging equipments and numerically by using computational simulations performed by means of specific software of fluid dynamics.

In literature, we found many experimental and computational investigations of blood flow in the human aortic arch, [4]-[7] (to name but some). The main objective of these studies has been to analyze the complex flow structures in the aortic arch and its branches and showing the effect of the geometry on the overall flow fields.

In order to enhance the performance of these models and to reflect the real situation, they have to correctly take into account several features like the non-Newtonian behavior of the blood, the unsteady and pulsatile aspects of the flow and the distension of the aortic wall. Hence, the role of the non-Newtonian behavior of the blood, which may be predominant under certain flow conditions [8], has been especially studied using various shear dependent viscosity models [9] [10]. Moreover, the pulsatile blood flow, which varies with the cardiac cycle, was shown to influence wall shear stress (WSS) [11]. Finally, the elastic behavior of the deformable walls revealed through the fluid-structure interaction studies has been intensively investigated [12] [13].

The main goal of this work is double. Firstly, we were interested in studying the simulation of the blood flow in thoracic aorta, by using some imported recent tridimensional magnetic resonance imaging data of a real healthy aorta and a real aorta in presence of coarctation, provided by "Laboratoire d'Imagerie Médicale-Université de Pierre et Marie Curie” (LIB-UPMC), in the context of a specific CFD software (ANSYS-ICEM-CFX), to build a meshing and elaborate an adapted geometry, and to examine the obtained results of the realized computational simulation. Secondly, we compared these results with those obtained from a computational simulation using the same software on a geometrical model of a healthy aorta proposed in [14], and another geometrical model of stenosis applied to coarctation developed in [15]. In all these cases, we examine the computational results concerning the blood flow velocity field as well as pressure and the WSS.

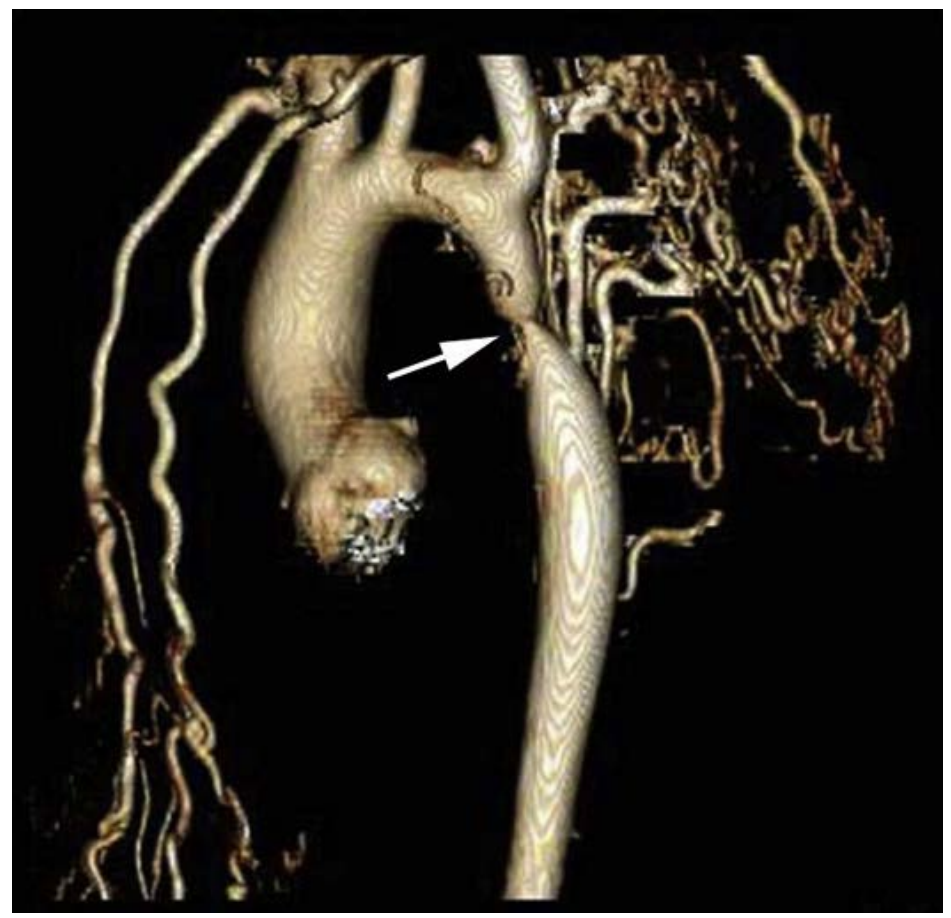

Figure 1. Computed tomographic 3D volume-rendered reconstruction of the thoracic aorta demonstrating severe aortic coarctation (arrow) and extensive collateral formation. 


\section{Assumptions, Considerations and MRI Imaging Technique}

Firstly, the blood is considered as an incompressible Newtonian fluid, which is generally accepted as a reasonable first approximation to the actual non-Newtonian behavior of blood at shear rates observed in large arteries [16]. Secondly, we consider the blood flow as steady stationary flow. Thirdly, we ignore the distensibility of the vessel walls, such that they are assumed to be smooth rigid (non-elastic) walls.

Furthermore, the blood fluid is assumed to have a density of $1.0595 \mathrm{gr} / \mathrm{cm}^{3}$, dynamical viscosity of $3.45 \mathrm{cp}$, and molar mass of $3527.89 \mathrm{~g} / \mathrm{mol}$.

In all our simulations, we apply the k- $\epsilon$ turbulence model with a Reynolds number $\operatorname{Re}=13,148$ for the first case (proposed aorta model without coarctation), $\mathrm{Re}=12,835$ for the second case (proposed aorta model with coarctation), $\operatorname{Re}=13,810$ in the third case (real aorta model without coarctation), and $\operatorname{Re}=27,046$ for the last case (real aorta model with coarctation). In order to ensure the convergence of each time step, we set the convergence criterion for the relative residual for all dependent variables equal to $1 \times 10^{-4}$. We also adopt the non-buoyant model, with subsonic flow regimen, normal speed of $150 \mathrm{~cm} / \mathrm{s}$, pressure profile bend of 0.05 , relative pressure of $60 \mathrm{mmHg}$ and reference pressure of $760 \mathrm{mmHg}$ (i.e. $1 \mathrm{~atm}$ ). Our computational simulation results using ANSYS-ICEM-CFX 13.0 concerns the profiles of pressure, velocity and WSS in the four cases.

Furthermore, the MRI technique allows measurement the blood flow. At the cardiovascular level, it permits to acquire not only dynamical anatomic images of heart and large vessels, but also functional images of blood flow by means of phase contrast. Applied to the thoracic aorta, this technique constitutes a reliable analysis method. Because of its noninvasive nature, it is the reference for the evolutionary track. For the diagnosis of diseases of the aortic wall, its use varies among centers. In fact, Velocity ENCoded gradient echo imaging (VENC), also known as phase contrast imaging, is an MR technique for quantifying blood flow velocities and volumes. Measuring the phase shift that occurs as protons in the blood move through a magnetic field, the velocity and direction of the blood can be obtained. In order to obtain accurate measurements from a phase contrast image, a plane must be selected perpendicular to the path of the flowing blood. The technique creates a velocity encoded image for multiple phases of the heart cycle, thus creating a cine dataset. In the cine produced, stationary tissue appears gray with tissue moving through the plane appearing as shades of either white or black, depending on the direction. The bright or dark the tissue is, the faster it is moving through the imaging plane. Quantification of blood flow is performed by software that requires the user to outline the vessel of interest on a single phase of the cardiac cycle and the remaining phases are automatically processed. The software produces thus time-velocity and time-flow curves. This technique is valuable for evaluating stenosis, in our case the coarctations. A pressure gradient across a lesion can be calculated from blood velocities. Blood flow is quantified from the individual blood velocities at each point over the cross section of the blood vessel [17] [18]. In the context of MRI protocols, $2 \mathrm{D}+\mathrm{t}$ phase contrast imaging of the aorta is the most commonly performed at selected anatomical levels, namely the ascending and descending aorta. However recently, the $3 \mathrm{D}+\mathrm{t}$ imaging which captures blood flow velocities in the entire aortic arch is proposed and is being used despite its long acquisition and processing times since it provides valuable clinical data in case of coarctation, aortic aneurysm or presence of bicuspid valve. Cine images are performed through the aortic arch and the region of the aortic isthmus at the junction of the aortic arch and the descending thoracic aorta just beyond the left subclavian artery, which is generally the common site of coarctation in adults. This permits to test the presence and the severity of an eventual coarctation at this site. Phase-contrast flow imaging is then realized to quantify volumes (aorta sections) and determine flow rate and velocity.

In this work, we used the LIB-UPMC imaging data concerning a healthy aorta and an aorta with a coarctation as well as data concerning the blood flow (aorta section, velocity and flow-rate). Using these imaging data, we constructed geometries of these two real aortas and performed on them the same computational simulation as used on our models, in order to compare results. We use also the blood flow imaging data to characterize aorta section, velocity and flow rate as well as the pressure field.

\section{Computational Simulation of Blood Flow in a Model of Healthy Aorta}

Firstly, in the proposed model, [14], we have represented the aorta arch as a $180^{\circ}$ curved circular tube with an interior radius of $0.37 \mathrm{~cm}$ and an external radius of $2.57 \mathrm{~cm}$, to be statistically in the average of real aorta sizes. We link to this tube a rectilinear cylindrical tube of diameter of $2.20 \mathrm{~cm}$ and length of $4 \mathrm{~cm}$ to represent a part of the descending aorta. The three principal aortic arteries are also represented by three cylinders with diameters of 
respectively $0.94 \mathrm{~cm}, 0.60 \mathrm{~cm}$ and $0.66 \mathrm{~cm}$. Using ICEM-CFX code, we obtain the following meshing (262410 nodes and 1,547,453 tetrahedral elements) and geometry (Figure 2). This configuration only models and approximately represents the real aortic arch.

In this first case, the computational simulation gives the following results (Figures 3-5).

\section{Computational Simulation of Blood Flow in an Aortic Model with a Coarctation}

Concerning, our model with coarctation, [15], we have deformed the previous model at the level of the beginning of the descending aorta, just below the left subclavian artery by inserting a geometrical deformation of hyperboloid aspect whose length is of $2 \mathrm{~cm}$ and reduction degree of $50 \%$, as illustrated below. Using ICEM-CFX code, we obtained the following meshing (246,010 nodes and 1,448,923 tetrahedral elements) and geometry (Figure 6).

In this second case, the computational simulation gives the following results (Figures 7-9).

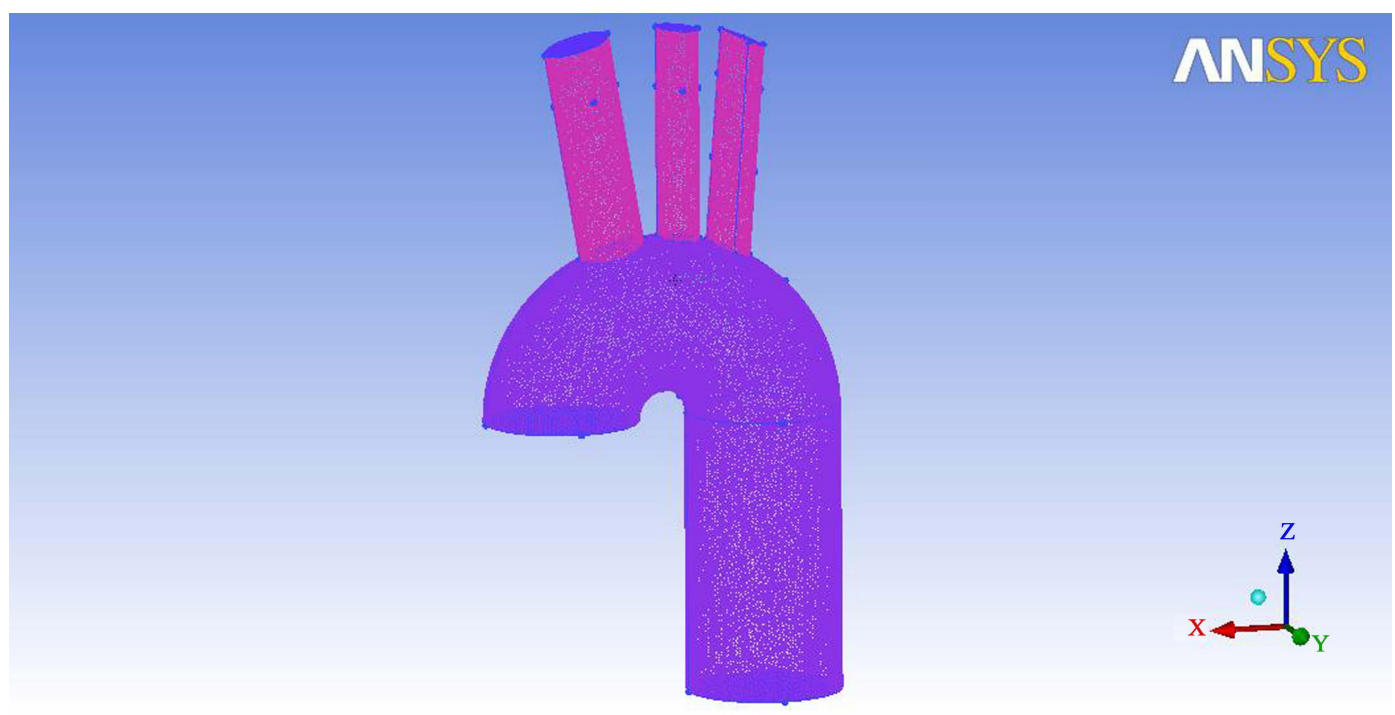

Figure 2. Meshing and geometry of the proposed model.

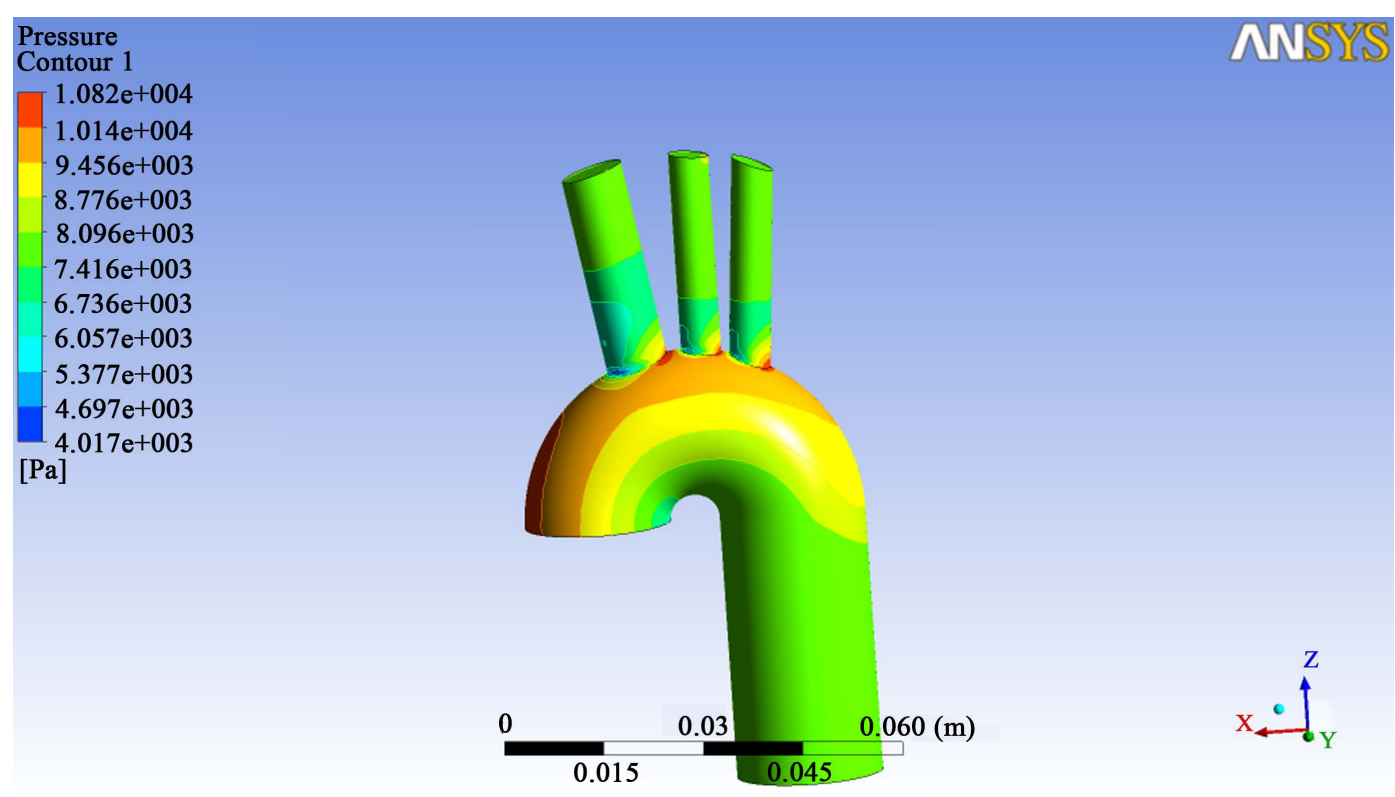

Figure 3. Pressure profile in the first case. 

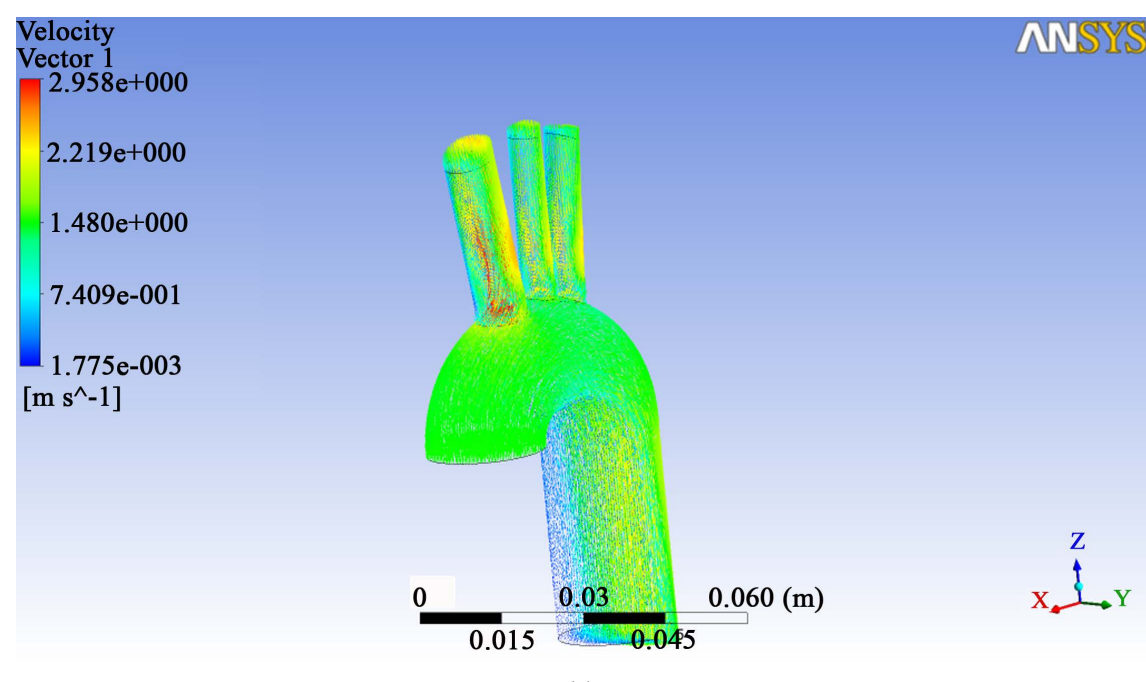

$2.219 \mathrm{e}+000$

$1.775 e-003$

$\left[\mathrm{m} \mathrm{s}^{\wedge}-1\right]$

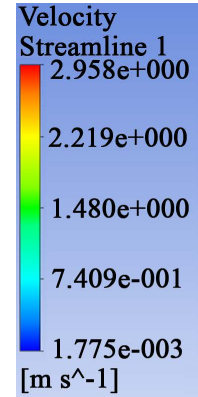

MNYS
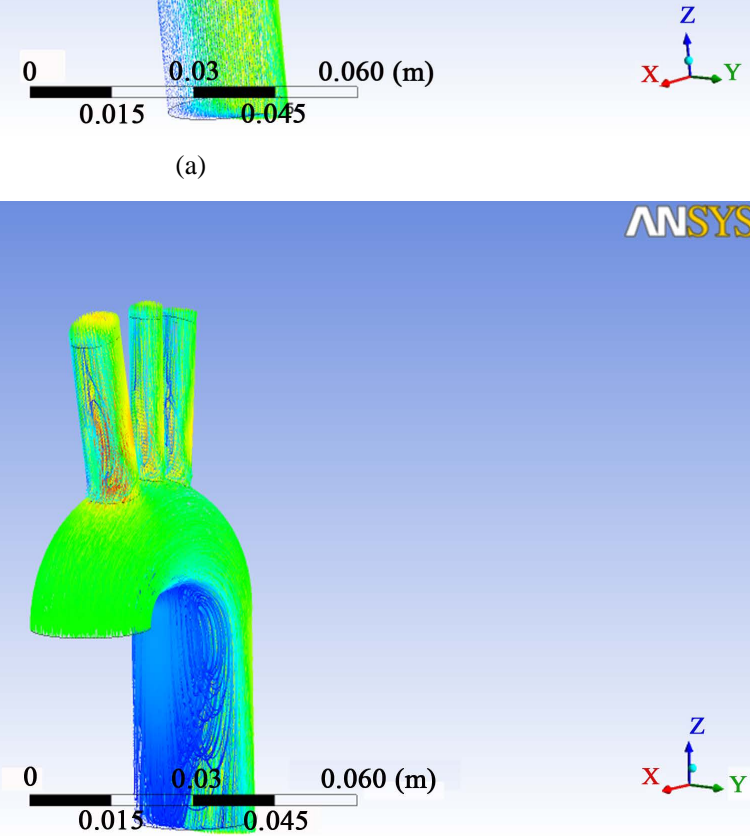

(b)

Figure 4. (a) Velocity profile (vector) in the first case; (b) Velocity profile (streamline) in the first case.
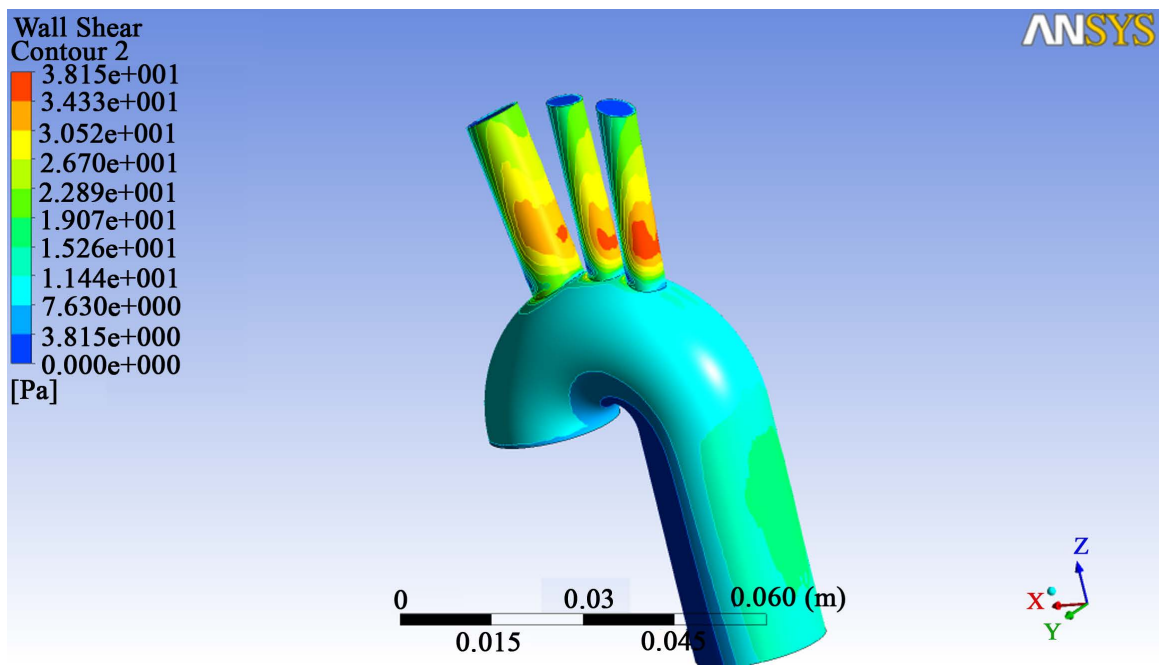
$[\mathrm{Pa}]$

Figure 5. WSS profile in the first case. 


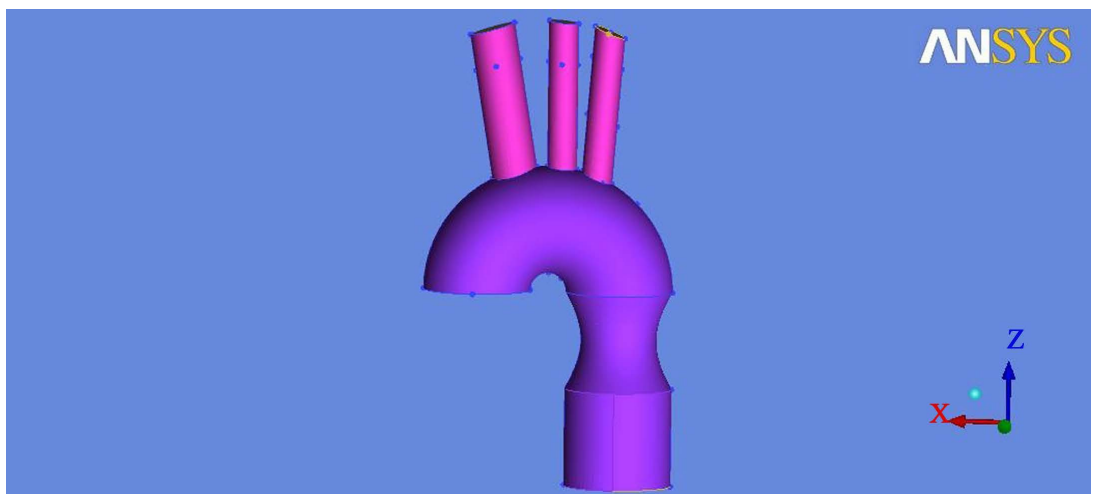

Figure 6. Meshing and geometry of the proposed model with coarctation.

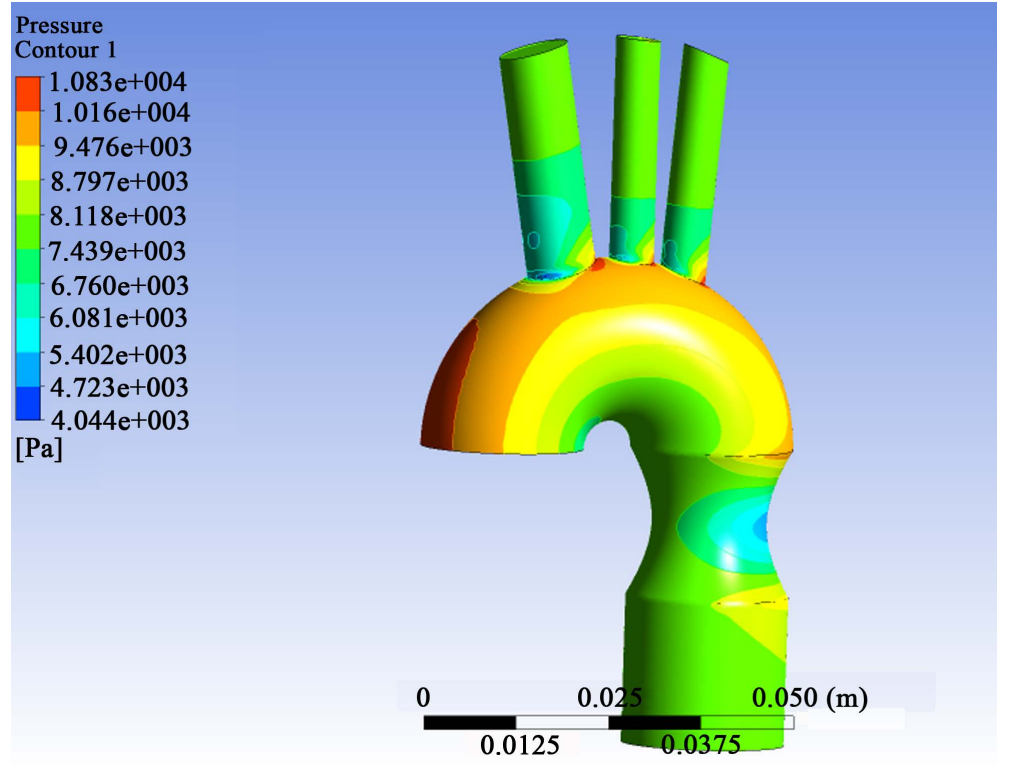

Figure 7. Pressure profile in the second case.

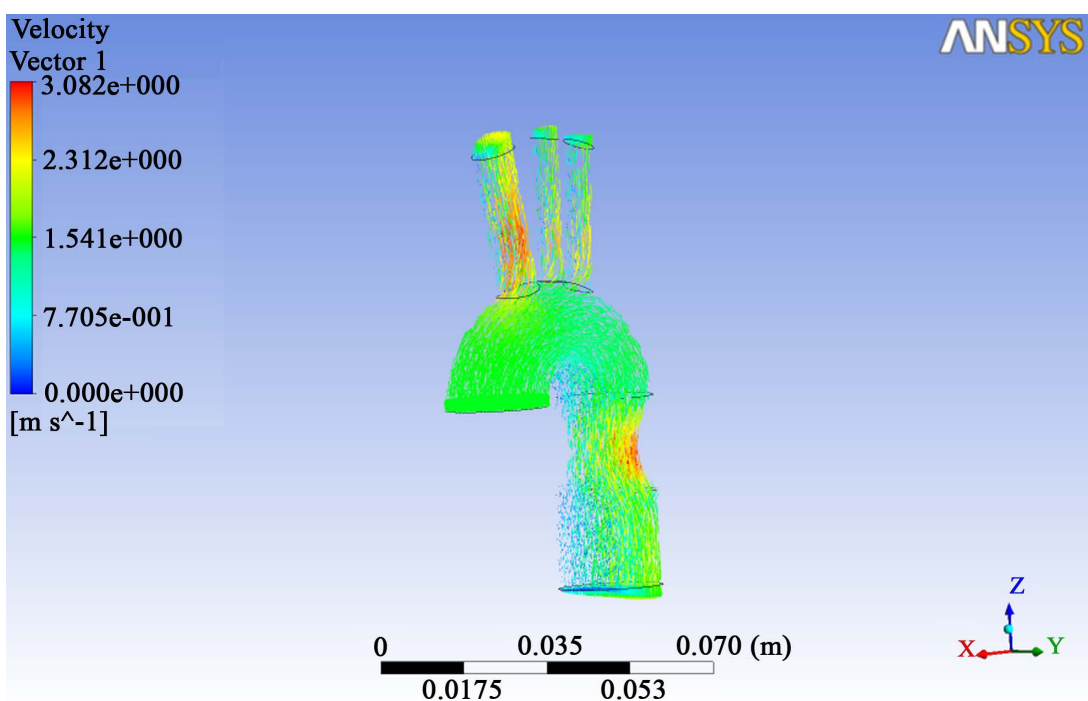

(a) 


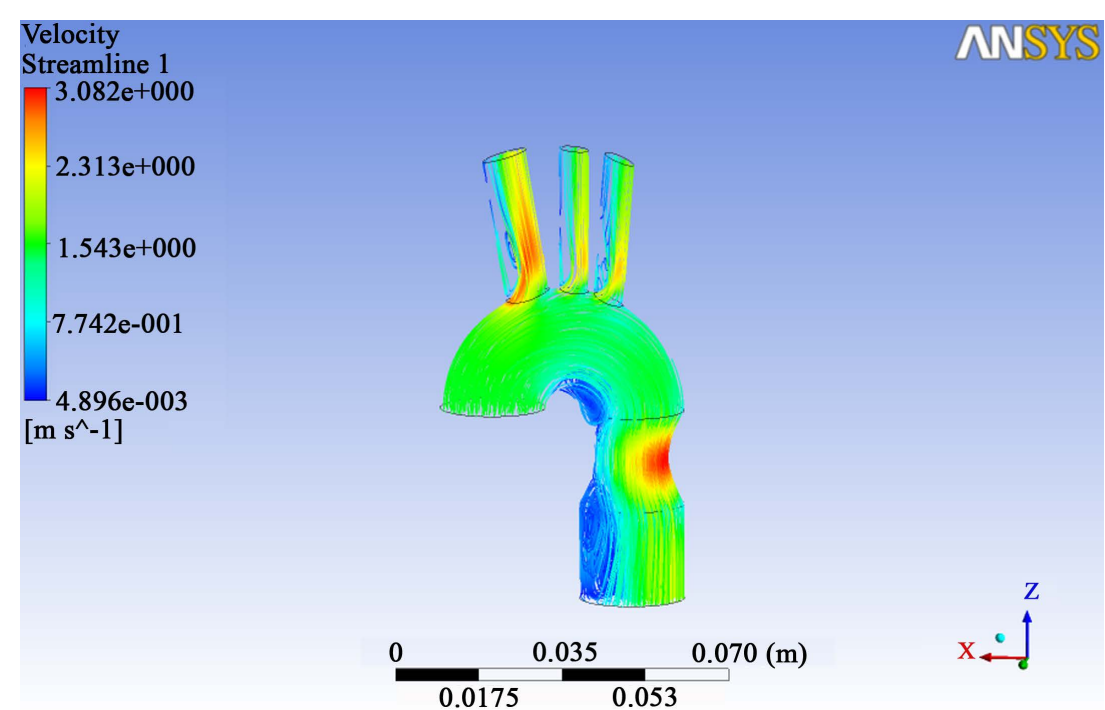

(b)

Figure 8. (a) Velocity profile (vector) in the second case; (b) Velocity profile (streamline) in the second case.

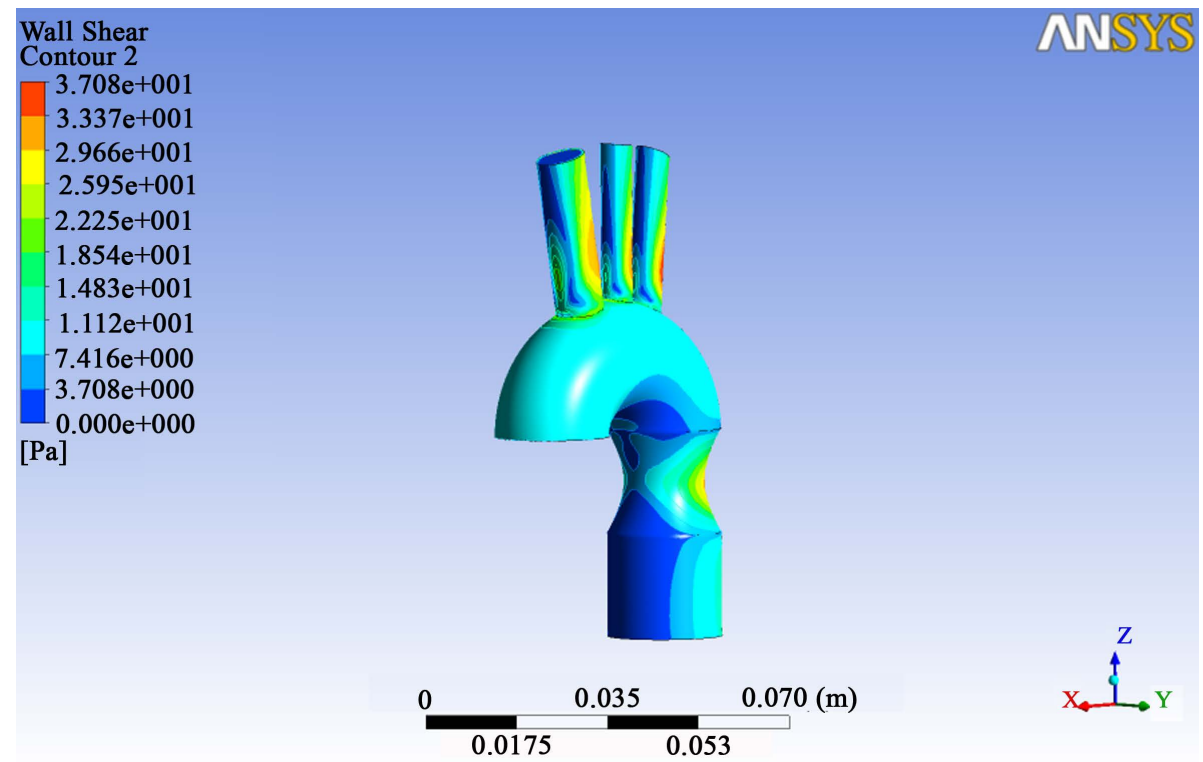

Figure 9. WSS profile in the second case.

\section{Computational Simulation of Blood Flow in a Real Healthy Aorta}

Importing imaging data concerning a real healthy human aorta, we have constructed its geometry using ICEM-CFX code, and we obtained the following meshing (148,319 nodes and 870,374 tetrahedral elements) and geometry (Figure 10).

In this third case, the computational simulation gives the following results (Figures 11-13).

\section{Computational Simulation of Blood Flow in a Real Aorta in Presence of a Coarctation}

Importing imaging data concerning a real human aorta with coarctation, we have constructed its geometry using ICEM-CFX code, and we obtained the following meshing (154,331 nodes and 901,105 tetrahedral elements) and 


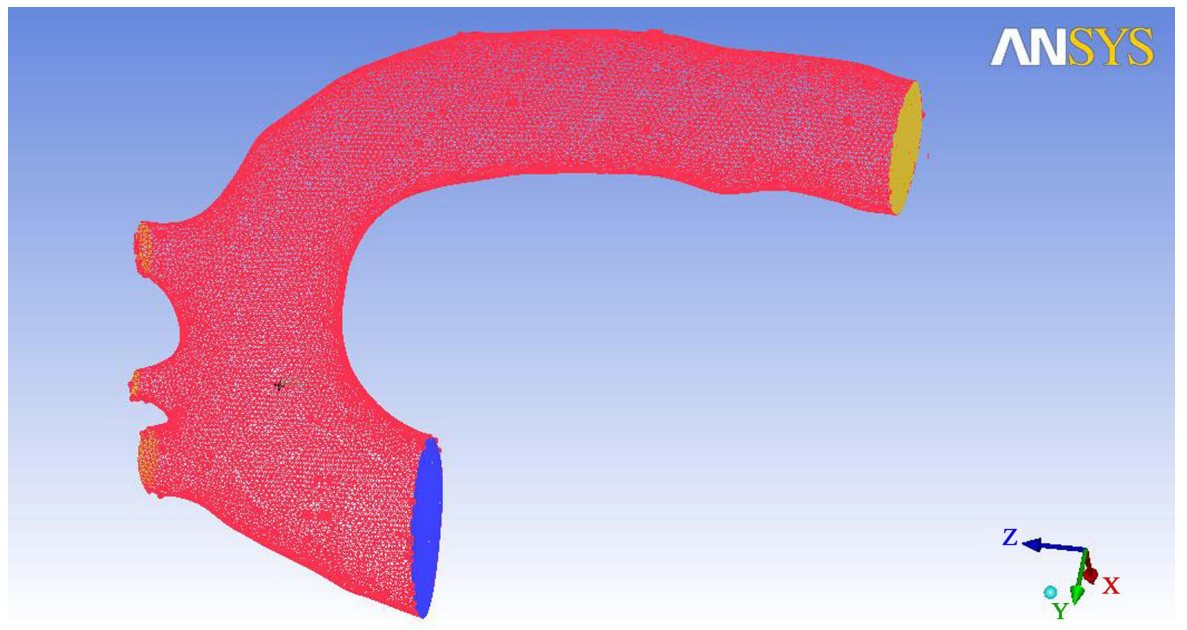

Figure 10. Meshing and geometry of the real model without coarctation.

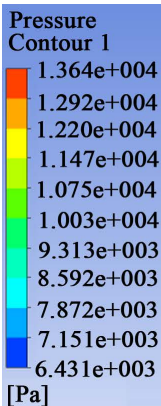
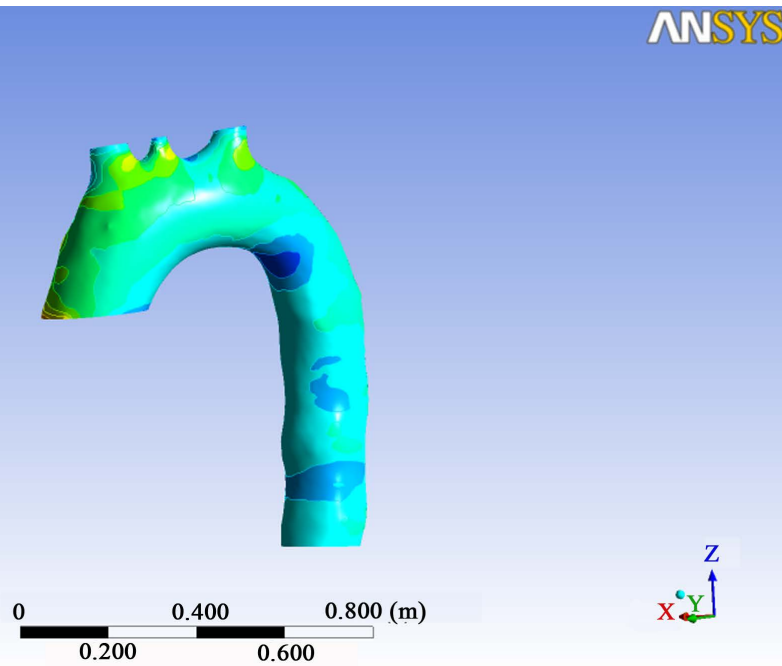
04 


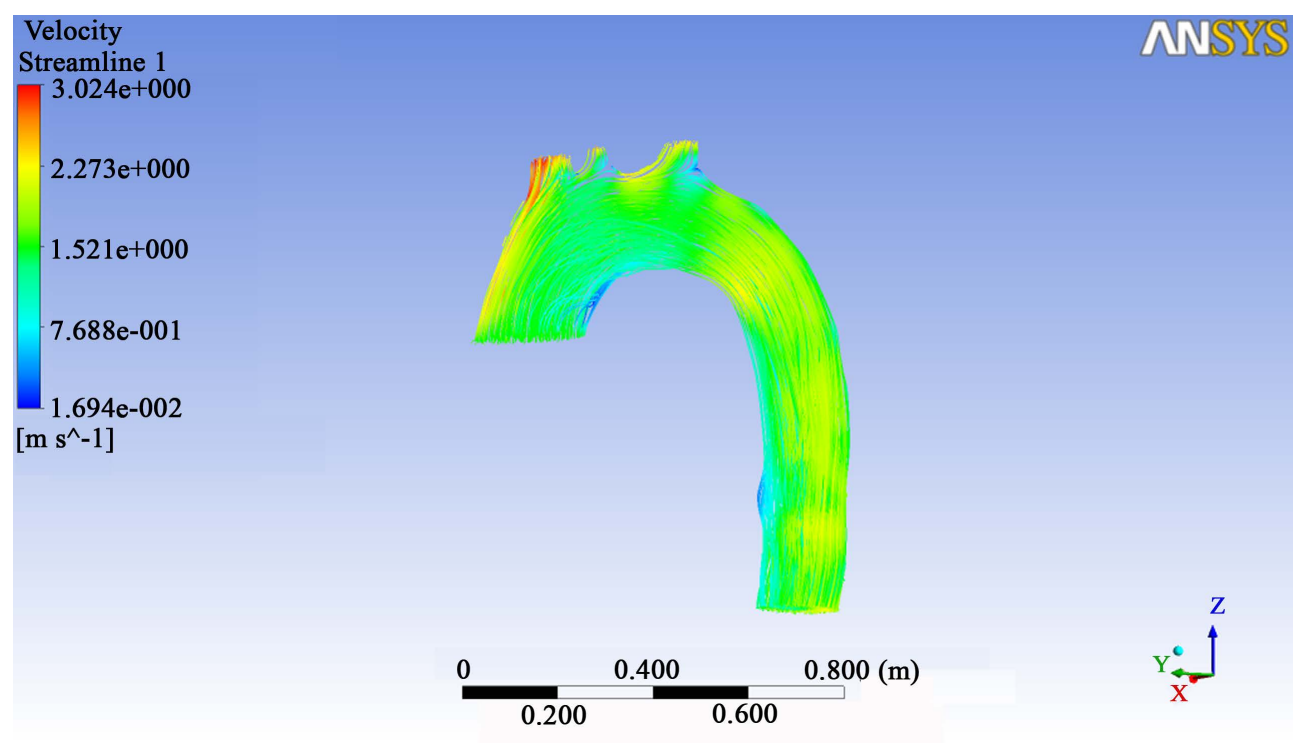

(b)

Figure 12. (a) Velocity profile (vector) in the third case; (b) Velocity profile (streamline) in the third case.

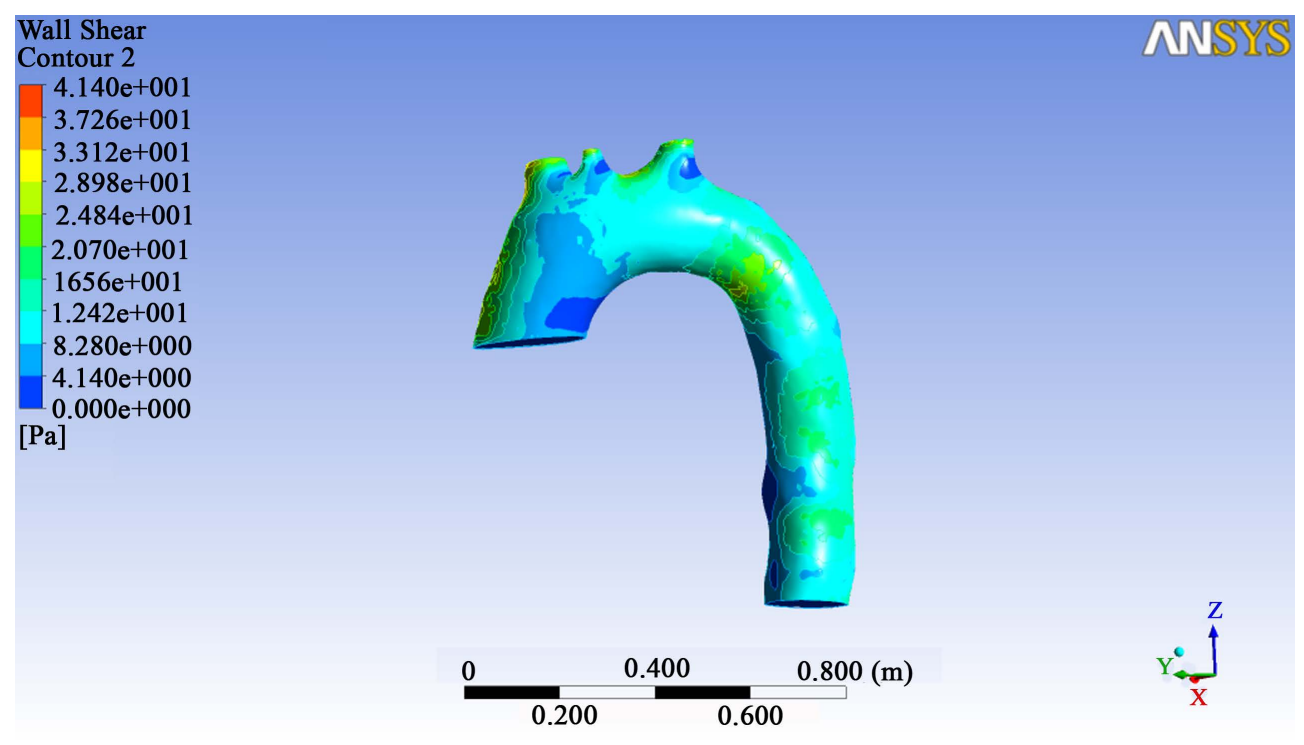

Figure 13. WSS profile in the third case.

geometry (Figure 14). Here, the length of the coarctation is equal to $2 \mathrm{~cm}$ and the reduction degree is nearly of $78 \%$.

In this fourth case, the computational simulation gives the following results (Figures 15-17).

\section{Discussions, Conclusions and Perspectives}

Comparing the results obtained for the case of a healthy aorta, the computational simulation gives practically the same profiles of pressure velocity and WSS for the real geometry and the proposed model. This permits us to say that our model without coarctation is a good model.

In the case of an aorta with a coarctation, the confrontation between the results obtained from the computational simulation for the case of the real model and the proposed model shows that there is a good agreement between them for velocity profiles as well as the minimal values of pressure and WSS. Nevertheless, there is a 


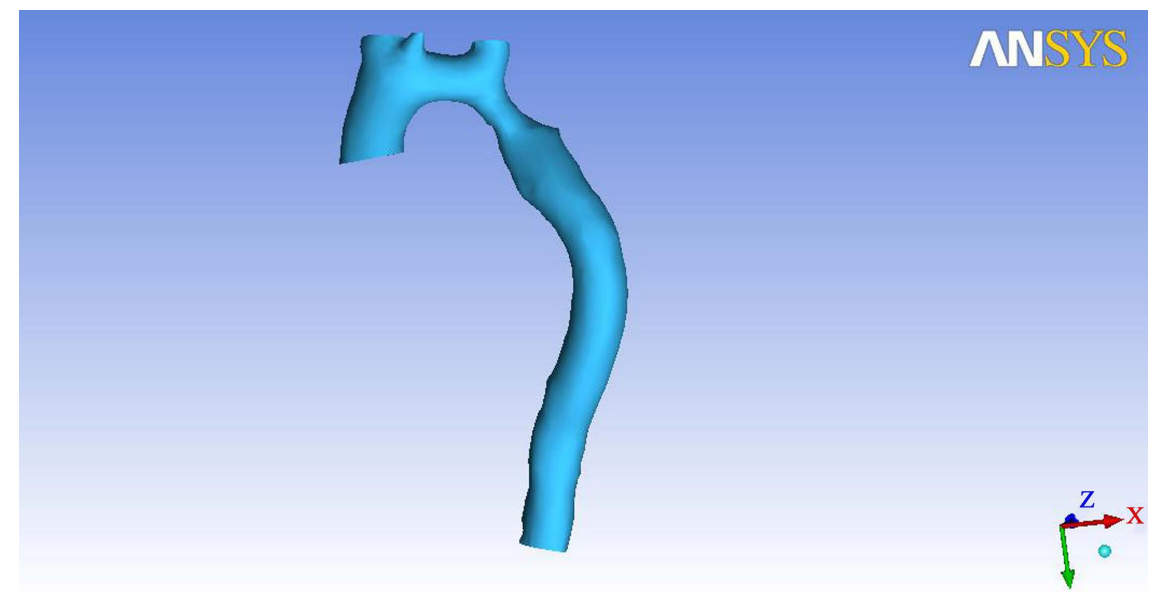

Figure 14. Meshing and geometry of the real model with coarctation.
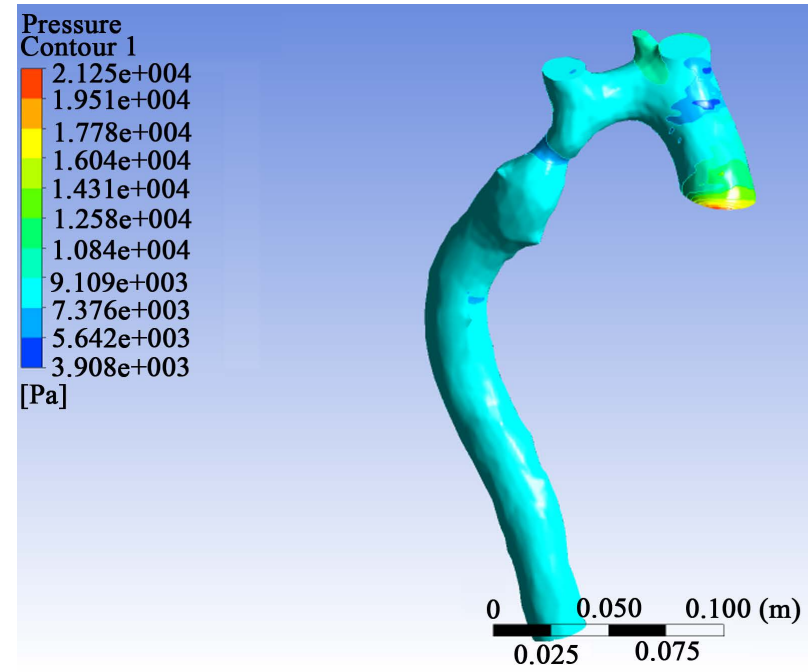

ANSYS

$2.125 \mathrm{e}+004$

$1.951 \mathrm{e}+004$

$1.778 \mathrm{e}+004$

$.604 \mathrm{e}+004$

$431 \mathrm{e}+004$

$.084 \mathrm{e}+004$

$109 e+003$

$.642 \mathrm{e}+003$

$\mathrm{Pa}]$

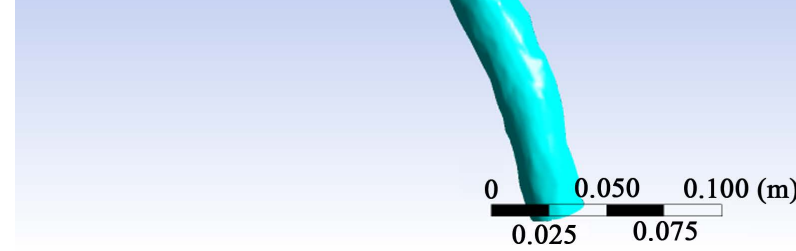

(a)
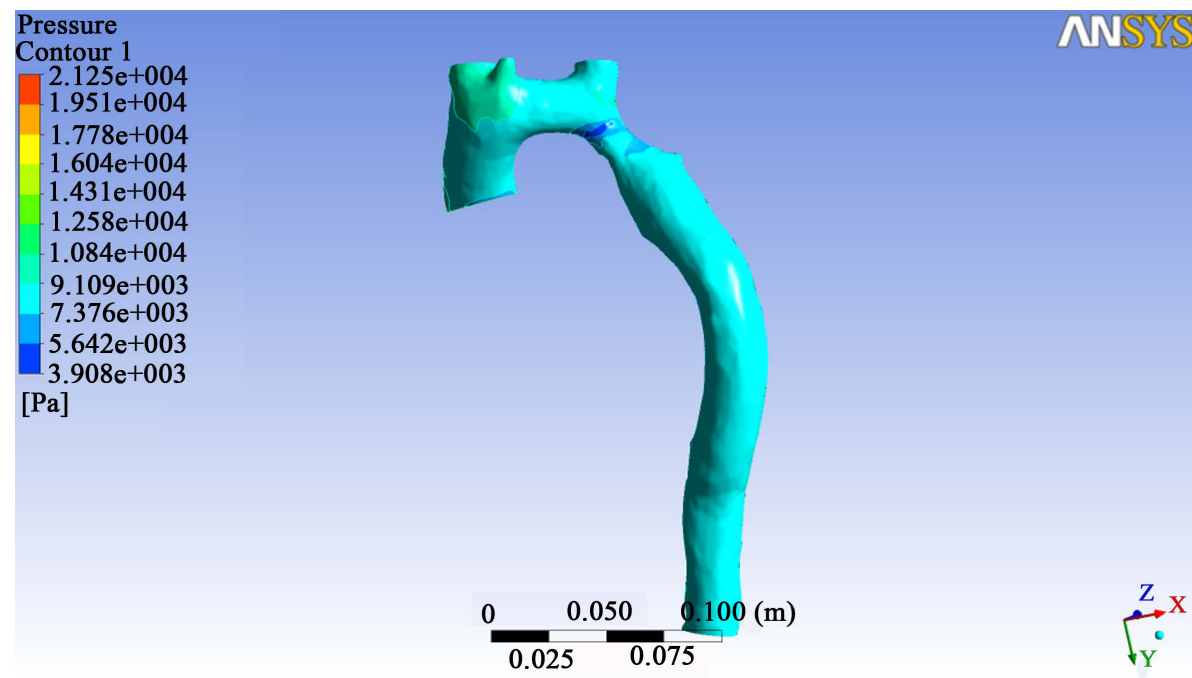

$1.258 \mathrm{e}+004$

$1.084 \mathrm{e}+004$

$9.109 \mathrm{e}+003$

$5.642 \mathrm{e}+003$

$3.908 \mathrm{e}+003$

\section{(b)}

Figure 15. (a) Pressure profile in the fourth case (view 1); (b) Pressure profile in the fourth case (view 2). 


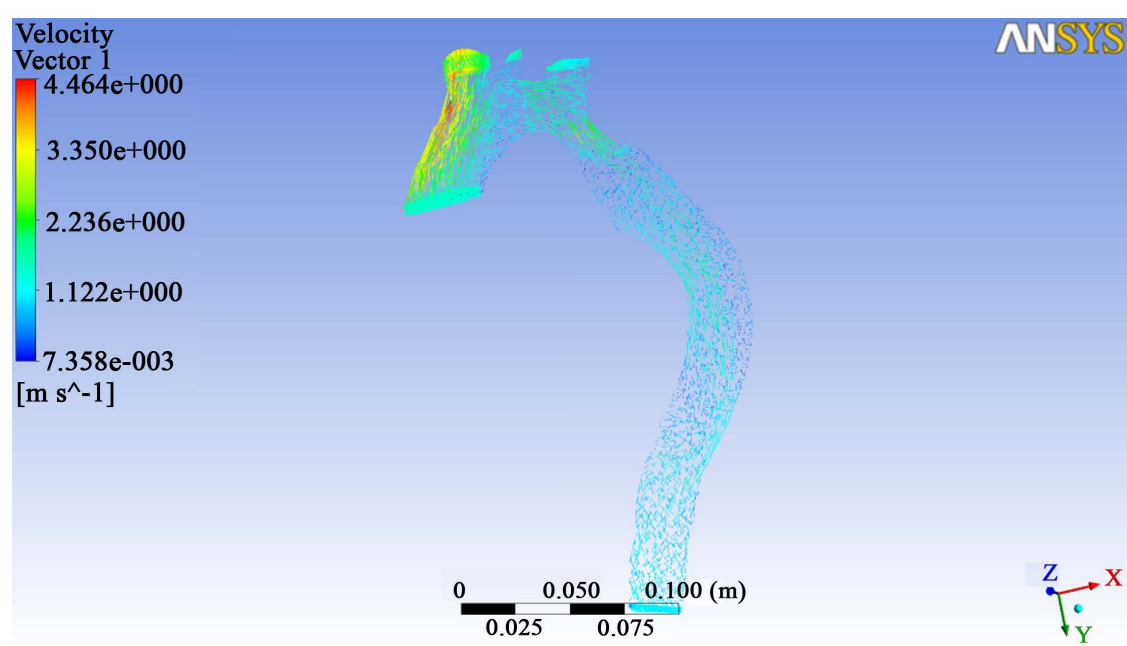

(a)
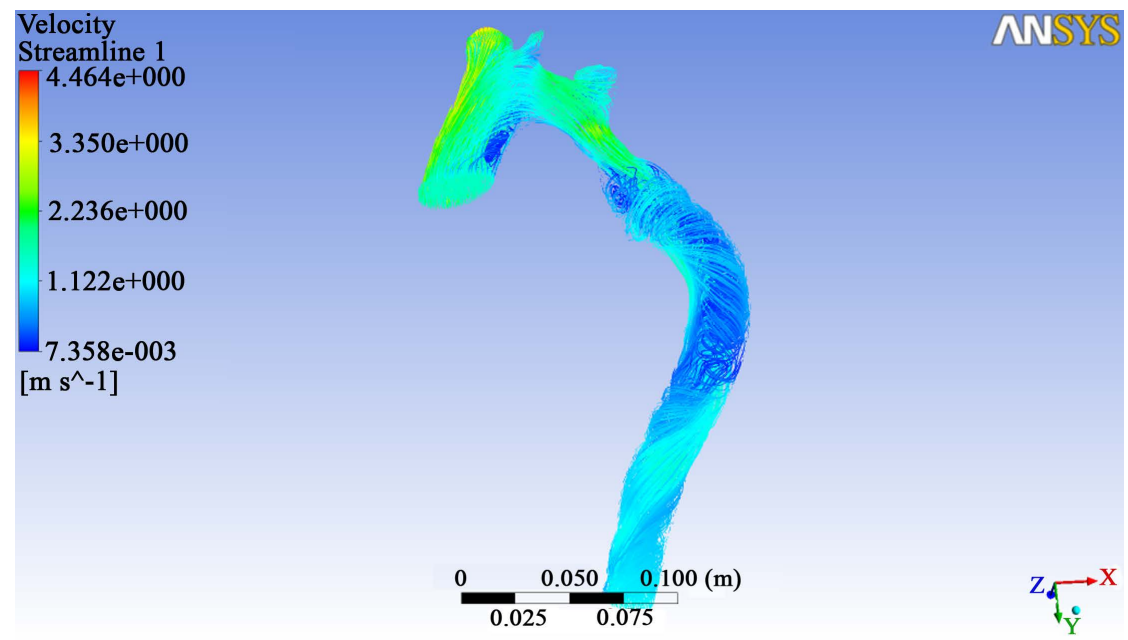

(b)

Figure 16. (a) Velocity profile (vector) in the fourth case; (b) Velocity profile (streamline) in the fourth case.

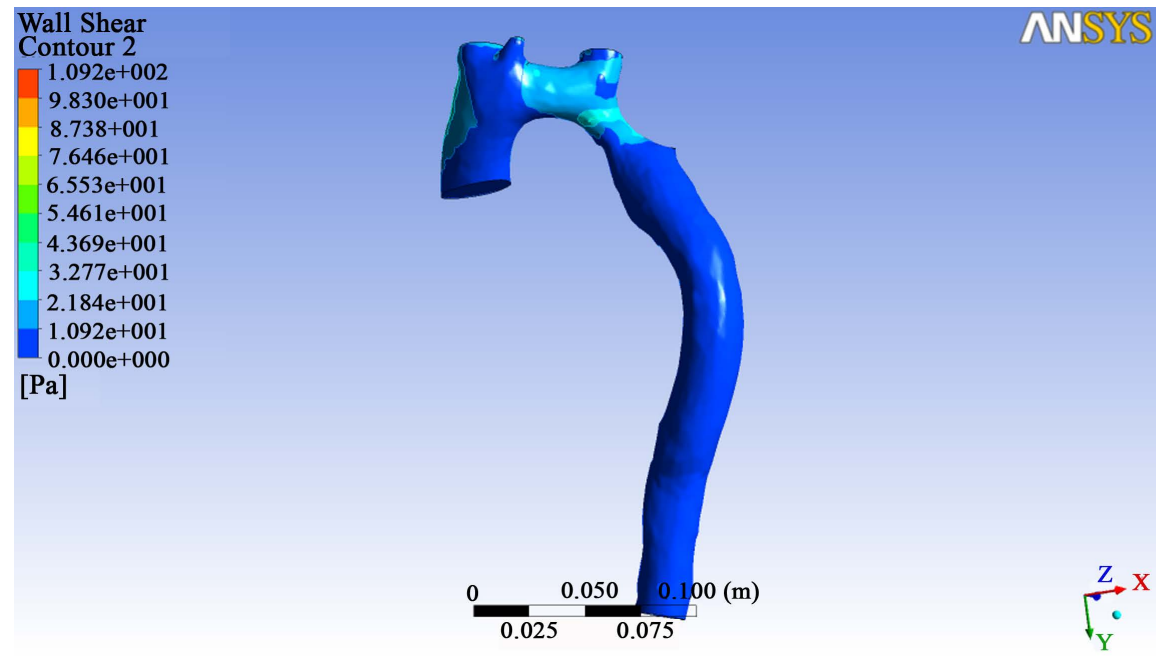

Figure 17. WSS profile in the fourth case. 
notable difference between the maximal value of pressure and WSS between the two cases. In fact, the maximal value of pressure in the case of real model is equal to 21,250 Pa, nearly the double of that for the case of proposed model $(10,830 \mathrm{~Pa})$, and the maximal value of WSS in the case of the proposed model is equal to 37.08 Pa whereas it is equal to $109.2 \mathrm{~Pa}$ in the case of real model. These disparities may be due essentially to the differences between the geometrical sizes of the real model and the proposed model and certainly also to the difference between the degree of reduction at the level of the coarctation in the two cases.

Despite these differences, our computational simulation has however allowed the partial validation of our model of aorta without and with coarctation. It remains to improve slightly this model in order to approach the most possible the real case.

We plan to treat the generalization of this work for the case of a pulsatile unsteady blood flow with taking into account the elasticity of the walls. In this case, the obtained results from computational simulation will be compared with the real measurements obtained in vivo by means of medical imaging tools.

As a continuity of this work, we plan also to treat in a future work the blood flow imaging data characterizing the aorta section, the velocity and the flow rate as well as the pressure field.

Furthermore, it is axiomatic that humans would have aortic arches with different sizes and with slightly different forms, depending on age and gender [19] [20]. So, we have also to take into account this aspect which is very important for surgery needs.

\section{Acknowledgements}

The authors are very grateful to H. Benali (Head of LIB-UPMC-Paris) and especially to N. Kachenoura (Head of cardiovascular imaging group at LIB-UPMC-Paris) for their crucial help, useful discussions and for providing them recent tridimensional magnetic resonance imaging data of a real healthy aorta and a real aorta in presence of coarctation, during their scientific visit at LIB-UPMC-Paris.

\section{References}

[1] Goldstein, S.A., et al. (2015) Multimodality Imaging of Diseases of the Thoracic Aorta in Adults: From the American Society of Echocardiography and the European Association of Cardiovascular Imaging, Endorsed by the Society of Cardiovascular Computed Tomography and Society for Cardiovascular Magnetic Resonance. Journal of the American Society of Echocardiography, 28, 119-182. http://dx.doi.org/10.1016/j.echo.2014.11.015

[2] Rosenthal, E. (2005) Coarctation of the Aorta from Fetus to Adult: Curable Condition or Lifelong Disease Process? Heart, 91, 1495-1502.

[3] Giordano, U., et al. (2009) Mid-Term Results, and Therapeutic Management, for Patients Suffering Hypertension after Surgical Repair of Aortic Coarctation. Cardiology in the Young, 19, 451-455.

[4] Yearwood T.L. and Chandran, K.B. (1984) Physiological Pulsatile Flow Experiments in a Model of the Human Aortic Arch. Journal of Biomechanics, 15, 683-704.

[5] Moore, J.E., et al. (1994) Fluid Wall Shear Stress Measurements in a Model of the Human Abdominal Aorta: Oscillatory Behavior and Relationship to Atherosclerosis. Atherosclerosis, 110, 225-240.

[6] Lei, M., et al. (1995) Numerical Investigation and Prediction of Atherogenic Sites in Branching Arteries. Journal of Biomechanical Engineering, 117, 350-357.

[7] Shahcheragi, N., et al. (2002) Unsteady and Three-Dimensional Simulation of Blood Flow in the Human Aortic Arch. ASME Journal of Fluids Engineering, 124, 378-387.

[8] Waite, L. and Fine, J. (2007) Applied Biofluid Mechanics. McGraw Hill, New York.

[9] Gijsen, F.J.H., et al. (1999) The Influence of the Non-Newtonian Properties of Blood on the Flow in Large Arteries: Unsteady Flow in a $90^{\circ}$ Curved Tube. Journal of Biomechanics, 32, 705-713.

[10] Prektold, K., et al. (1991) Pulsatile Non-Newtonian Flow Characteristics in a Three-Dimensional Human Carotid Bifurcation Model. Journal of Biomechanical Engineering, 113, 464-475. http://dx.doi.org/10.1115/1.2895428

[11] Shaaban, M.A. and Duerinckx, J. (2000) Wall Shear Stress and Early Atherosclerosis. AJR, 174, 1657-1665. http://dx.doi.org/10.2214/ajr.174.6.1741657

[12] Tsangaris, S. and Pappou, Th. (1999) Flow Investigation in Deformable Arteries. In: Verdonck, P. and Prektold, L., Eds., Intra and Extracorporal Cardiovascular Fluid Dynamics, WIT Press, Southampton, 291-332.

[13] Prektold, K. and Prosi, M. (2003) Computational Models of Arterial Flow and Mass Transport. In: Pedrizetti, G. and Prektold, K., Eds., Cardiovascular Fluid Mechanics, Springer, Berlin, 73-134. 
[14] Moumen, M. (2010) Etudes des effets turbulent de l'écoulement sanguine dans la crosse aortique. Théorie et simulation. Magister Thesis, University of Oran Es-sénia, Oran.

[15] Moumen, M. and Djemaï, A.E.F. (2016) Computational Simulation of Blood Flow in the Case of a Geometrical Model of Left Subclavian Artery Stenosis. Communication accepted to be presented at $8^{\text {th }}$ EPFCD2016, Warsaw, July 2016.

[16] Perktold, K., et al. (1991) Pulsatile Non-Newtonian Blood Flow in Three-Dimensional Carotid Bifurcation Models: A Numerical Study of Flow Phenomena under Different Bifurcation Angles. Journal of Biomedical Engineering, 13, 507-515.

[17] Khalifé, M. (2013) Mesure de pression non-invasive par imagerie cardiovasculaire et modélisation unidimensionnelle de l'aorte. Doctorate Thesis, University Paris XI.

[18] https://www.med-ed.virginia.edu/courses/rad/cardiacmr/Techniques/VENC.html

[19] Wolak, A., et al. (2008) Aortic Size Assessment by Noncontrast Cardiac Computed Tomography: Normal Limits by Age, Gender, and Body Surface Area. JACC: Cardiovascular Imaging, 1, 200-209.

[20] Redheuil, A., et al. (2011) Age-Related Changes in Aortic Arch Geometry-Relationship with Proximal Aortic Function and Left Ventricular Mass and Remodeling. Journal of the American College Cardiology, 58, 1262-1270. http://dx.doi.org/10.1016/j.jacc.2011.06.012

\section{Submit or recommend next manuscript to SCIRP and we will provide best service for you:}

Accepting pre-submission inquiries through Email, Facebook, Linkedin, Twitter, etc A wide selection of journals (inclusive of 9 subjects, more than 200 journals)

Providing a 24-hour high-quality service

User-friendly online submission system

Fair and swift peer-review system

Efficient typesetting and proofreading procedure

Display of the result of downloads and visits, as well as the number of cited articles

Maximum dissemination of your research work

Submit your manuscript at: http://papersubmission.scirp.org/ 